Revista de la red interuniversitaria de estudios sobre las literaturas rioplatenses contemporáneas en Francia

17 | 2017

Hermetismo programático en la literatura rioplatense contemporánea (de 1980 a nuestros días)

\title{
Lo privado vuelto público: el insilio en una escritura poético-política
}

Andrea Carriquiry

\section{OpenEdition}

\section{Journals}

Edición electrónica

URL: http://journals.openedition.org/lirico/3967

DOI: $10.4000 /$ lirico.3967

ISSN: 2262-8339

Editor

Réseau interuniversitaire d'étude des littératures contemporaines du Río de la Plata

Referencia electrónica

Andrea Carriquiry, «Lo privado vuelto público: el insilio en una escritura poético-política », Cuadernos LIRICO [En línea], 17 | 2017, Publicado el 09 diciembre 2017, consultado el 25 septiembre 2020. URL http://journals.openedition.org/lirico/3967 ; DOI : https://doi.org/10.4000/lirico.3967

Este documento fue generado automáticamente el 25 septiembre 2020

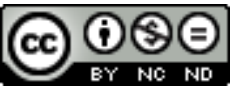

Cuadernos LIRICO está distribuido bajo una Licencia Creative Commons Atribución-NoComercialSinDerivar 4.0 Internacional. 


\section{Lo privado vuelto público: el insilio en una escritura poético-política}

\section{Andrea Carriquiry}

REFERENCIA

Oroño, Tatiana. Libro de Horas. Montevideo: Estuario Editora, 2017, 140 p. 
1 Tatiana Oroño es poeta, crítica de artes visuales y docente de literatura. En poesía publicó El alfabeto verde (1979); Poemas (1982); Cuenta abierta (1986); Tajos (1990); Bajamar (1996); Tout fut ce qui ne fut pas (Marsella, 2002); Morada móvil (2004); La piedra nada sabe (2008); Ce qu'il faut dire a des fissures (París, 2012), Estuario (2014). Su obra ha sido traducida, premiada e incluida en los programas educativos oficiales en Uruguay. Es investigadora asociada a la Academia Nacional de Letras. Además, es hija de Dumas Oroño, destacado integrante del Taller Torres García.

2 Libro de horas es una «autobiografía poética» que recorre algunos capítulos de la vida de su autora. Se destacan su niñez alternando con integrantes del Taller Torres García, su vivencia de la dictadura

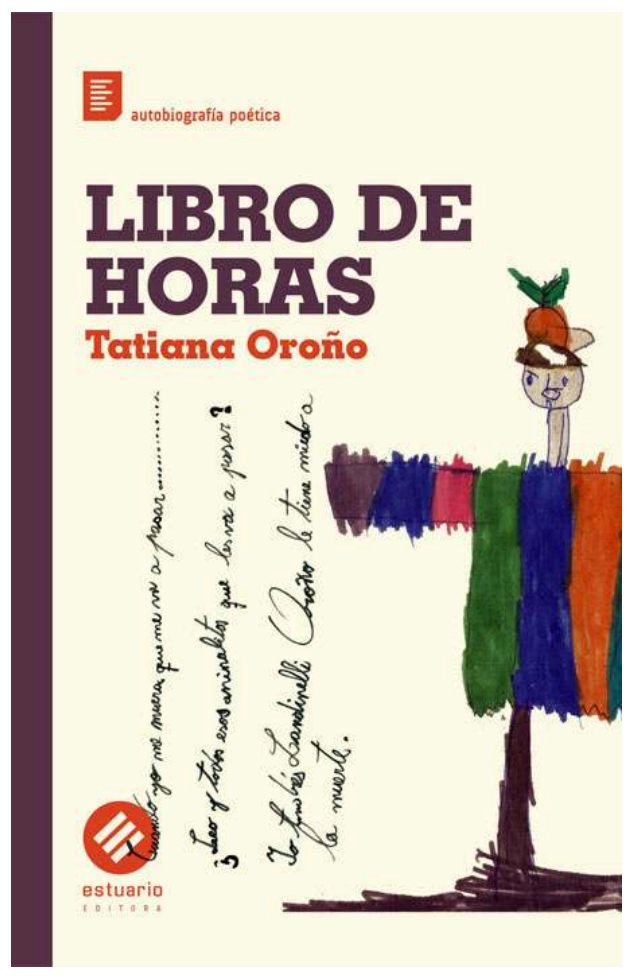
como profesora destituida, su actividad como docente de literatura, su maternidad y posterior abuelazgo. Oroño da voz a experiencias poco contadas, de sujetos que están como en la periferia de la periferia, que tienen un lugar subalterno, pero que además no son fáciles como materia literaria. Voy a detenerme en dos de esas miradas periféricas: la maternidad y el llamado insilio (es decir, la situación de quienes permanecieron en el país durante la dictadura cívicomilitar, una situación que se define por negaciones: no presos, no exiliados, solo «apresados en la lucha por la vida y el sustento» ${ }^{1}$ ).

Un rápido repaso por el imaginario de las escritoras uruguayas más conocidas permite preguntarse si la maternidad ha sido un tema central en su producción (aunque obviamente haya sido abordado puntualmente: el caso de Juana de Ibarbourou es el más notorio). El plano en el que aparece la relación madre-hijo, en todo caso, recorre este libro, y está especialmente concentrado en la parte VII, titulada «Casas». Es la zona iluminada del libro de horas, gracias a los dibujos infantiles que allí figuran, la mayoría en color. Son facsímiles de las creaciones de los hijos y nietos de la autora, que ella ha guardado; los comenta uno a uno. En la tradición de los mejores críticos y divulgadores de arte, Oroño apunta a la difícil tarea de que el texto diga algo más que la imagen. Y trabaja cómodamente en esa intersección: su padre fue artista, ella misma es crítica de arte; se advierte una naturalidad en el trato, en el ida y vuelta entre literatura y artes visuales ${ }^{2}$. El resultado constituye uno de los tramos más originales de esta obra.

Por otro lado, un lapso importante de la maternidad tratada en Libro de horas fue vivida en dictadura. La autora declara en una entrevista reciente que fue madre de «hijos de los vencidos», en la formulación de Lidia Falcón ${ }^{3}$. Es la maternidad de mujeres que habían soñado un mundo mejor para sus hijos, y terminan criándolos en un mundo mucho peor. Sin embargo, este no es un libro oscuro. Eso parece consecuente con la intención militante que aparece como central en la resistencia de la autora a la dictadura: ante todo, no dejar «que te roben el alma» ${ }^{4}$. La autora se empecina en contar 
su historia, en inyectarle sentido y explicitarlo. Se resiste también al amigo que en algún momento le dice "escribir sobre la memoria siempre es una causa perdida» ${ }^{5}$. El objetivo del libro parece ser que, tampoco en la memoria, nos roben el alma.

Más en general, cabe hacer notar dos aspectos contrapuestos de la experiencia del insilio. Por una parte, como señala Marisa Silva Schultze -quien ha abordado el período dictatorial como escritora de ficción y como historiadora- «hemos hecho una especie de pirámide con relación a las víctimas de la dictadura. Los que fueron destituidos, o estuvieron apenas unos meses presos, o vivieron en el país la dureza de esos tiempos, esta gente ha hablado muy poco, porque cree que lo importante es lo otro» ${ }^{6}$. Sin embargo, es relevante recordar que, como han marcado los estudios de Alfred Stepan y Charles Gillespie, y como destaca Álvaro Rico ${ }^{7}$, la dictadura uruguaya ocupa un triste primer lugar en la región: Uruguay es «el país que más se acerca a experimentar el clima de un estado totalitario», "con niveles de vigilancia y control social que alcanzaron los límites más elevados del tipo ideal autoritario».

6 Desde este punto de vista, se podría pensar que el tipo particular de violencia que sufrió la población insiliada tuvo como una de sus consecuencias el recluirla en lo más privado. Ello está en relación con un aspecto significativo de esta obra de Oroño. Como observa Norah Giraldi Dei Cas, Libro de horas «surge en la esfera de lo privado pero rápidamente toma otro sentido: la historia personal se enlaza con la del país» ${ }^{10}$. Toda autobiografía puede volverse un monólogo ensimismado y críptico. Una «autobiografía poética» duplica ese riesgo. Este libro, sin embargo, sortea tales peligros gracias a cierta vocación de apertura al diálogo. En ese sentido, se lo podría leer en la línea de lo que Jürgen Habermas ha descrito como "privacidad orientada a una audiencia»" Justamente, el filósofo alemán acuña esta noción al analizar, en particular, la escritura de cartas como «una impresión del alma», una "visita del alma» (Abdruck der Seele, Seelenbesuch) y el posterior género de la novela epistolar durante el siglo XVIII, en el marco del surgimiento de una esfera pública literaria. Me interesa señalar este punto de contacto, visible también en Roberto Appratto, un escritor también insiliado que en Se hizo de noche aborda sus memorias del período dictatorial con una prosa poética de difícil clasificación: al reflexionar sobre el rol que ocupó la escritura durante la dictadura, Appratto escribe: «Me esforzaba por encontrar un punto de inflexión para mi voz. Algo así como una caja de resonancias, ese ámbito para lo sonoro íntimo del que por el momento, por ese largo momento, había sido privado»"1213.

7 Se podría decir entonces que con Libro de horas su autora intenta, en un movimiento inverso al que sufrió durante la dictadura, salir de la experiencia privada, haciéndola pública. Si durante la dictadura su estrategia se centró en "que no nos roben el alma», es decir en conservar lo más privado como reducto al que no pueda llegar el estado totalitario, la escritura posterior (el Libro de horas) intenta releer esa preservación de lo privado como una actitud política, e intenta además ese movimiento inverso de hacer pública esa experiencia privada.

El medio que elige es la literatura. Escribir aparece entonces como una respuesta posible a una pregunta que se repite en otros casos similares: ¿qué hacer con lo que pasó en la dictadura?: «qué hacía yo con lo que había perdido» escribe Appratto14, «Qué hacer con lo no dicho», titula Marisa Silva Schultze ${ }^{15}$, «qué hacer con la tortura» nos cuenta Carina Blixen que se pregunta Stella Reyes, una expresa política partícipe del libro Los ovillos de la memoria ${ }^{16}$. La literatura viene a responder parcialmente esa 
pregunta: viene, por lo menos, a hacer pública esa pregunta, intentando atravesar «la casi imposibilidad de hacerse entender ${ }^{17}$.

La dictadura generó, entre otras cosas, un hiato o extrañamiento entre generaciones los «hijos de los vencidos», los vencidos mismos, los que fueron adolescentes en dictadura, los que nacieron ya en democracia y escuchan, ya hastiados: «vos no eras nacido». Como destaca Carina Blixen en Huyssen, la memoria representa «un proceso que debe empezar en el individuo pero que solo puede completarse exitosamente si es sustentado por la instancia colectiva, por toda la sociedad $»^{18}$. En este sentido, quizás las escrituras asociadas a la experiencia del insilio puedan permitir un acercamiento de públicos diversos, como en una especie de círculos concéntricos. Por usar una metáfora clásicamente femenina: quien haya intentado la ciencia del zurcido sabe que para reparar un tejido roto, sin importar la magnitud del hueco, primero se lo atraviesa con un hilo, después se entrecruza otro, y así, con paciencia invisible. Libro de horas es un hilo.

\section{NOTAS}

1. Tatiana Oroño, Libro de horas, Montevideo: Estuario Editora, 2017, p. 38.

2. Asumo como supuesto algo que no voy a argumentar aquí: que las creaciones de los niños merecen carta de ciudadanía, como diría el filósofo norteamericano Arthur Danto, en las artes visuales.

3. Gabriel Lagos, «Memoria poética», La Diaria, 26/10/2017.

4. Tatiana Oroño, op. cit., p. 26.

5. Tatiana Oroño, op. cit., p. 73.

6. Marisa Silva Schultze, Qué hacer con lo no dicho, Montevideo: Alfaguara, 2008 [1999], p. 168. La declaración aparece en una entrevista de Lil Bettina Chouhy a la autora, incluida en la segunda edición del libro, de 2008.

7. Cuando analiza como uno de los rasgos distintivos de la dictadura uruguaya «el carácter totalitario-disciplinador del régimen: la sociedad vigilada», Rico señala: «La Declaración de Fe Democrática, la categorización de ciudadanos en categorías A, B, y C, la suspensión de derechos por 15 años a miles de políticos, el registro de vecindad, las censuras a la prensa y a la cultura, entre muchas otras, son medidas que ilustran el sistema generalizado de control y vigilancia impuesto a la población en su conjunto por la dictadura» (Álvaro Rico, «La dictadura uruguaya vista desde la teoría política. (I) Sobre la caracterización y la «especificidad» de la dictadura uruguaya», en Álvaro Rico, Carlos Demasi y Vania Markarian, Historia del Uruguay. Tercera Parte (1971-2004), ANEP: Montevideo, 2006, disponible en <http://www.anep.edu.uy/historia/clases/ clase27_2/programa_c27_1_2.html>, página consultada el 15/09/2017.

8. Alfred Stepan citado en Álvaro Rico, op. cit.

9. Charles Gillespie citado en Álvaro Rico, op. cit.

10. Texto de contratapa en Tatiana Oroño, op. cit.

11. Jürgen Habermas, Strukturwandel der Öffentlichkeit, Frankfurt am Main: Suhrkamp, 1962.

12. Ibidem, p. 48-49.

13. Aquí aparece la acepción de «privado» como 'carente', que Habermas analiza también en su trabajo de 1961 (op. cit.) 
14. Roberto Appratto, op. cit., p. 25.

15. Marisa Silva Schultze, Qué hacer con lo no dicho, Montevideo: Alfaguara, 2008 [1999].

16. «Stella Reyes hablaba de la tortura con la delicadeza que surgía de su persona y se preguntaba qué hacer con ella. Porque - decía- uno hace el duelo de sus muertos queridos (su hermana Silvia fue asesinada la noche del 20 al 21 de abril de 1974), de sus desaparecidos queridos (dijo que espera saber como desapareció su cuñado Washington Barrios y que devuelvan sus restos); pero no sabe qué hacer con la tortura que vuelve intacta al recordar». En Carina Blixen, «Deber de memoria y derecho al olvido: testimonio y literatura a partir de la experiencia de la dictadura cívico-militar (1973-1985) en Uruguay», en Actas de La mémoire et ses représentations esthétiques en Amérique Latine, Rennes, 2010, p. 6, disponible en <http://www.apuruguay.org/sites/default/ files/Blixen-C-Memoria-olvido-v\%C3\%ADctima.pdf>, página consultada el 15/09/2017.

17. Roberto Appratto, op. cit., p. 37.

18. Andreas Huyssen, Después de la gran división, Buenos Aires: Adriana Hidalgo, 2006, p. 175, citado en Carina Blixen, op. cit., p.2.

\section{AUTORES}

\section{ANDREA CARRIQUIRY}

Instituto de Filosofía

Facultad de Humanidades y Ciencias de la Educación

Universidad de la República (UDELAR, Uruguay)

andrea.carriquiry@gmail.com 